\title{
SYNTHESIS AND CHARACTERIZATION OF THERMALLY STABLE NOVEL POLYMERS CONTAINING PHENYLTHIOUREA, AZO AND SULFONE GROUPS IN THE BACKBONE
}

\author{
MYLSAMY SIVADHAYANITHY*, LINGAM RAVIKUMAR ${ }^{I}$, AND T.RAMACHANDRAN²
}

\author{
*2Department of chemistry, Amrita Vishwa Vidyapeetham \\ Amrita School of Engineering, Coimbatore-641 105, India. \\ ${ }^{1}$ Department of chemistry, C.B.M.College, Coimbatore-641 042, India. \\ (Received $28^{\text {th }}$ February 2007 - Accepted $15^{\text {th }}$ May 2007)
}

\begin{abstract}
:
The present work deals with the synthesis of thermally stable polymers that contain phenylthiourea, sulfone and azo group in the backbone from bisphenol and diacid chlorides. The bisphenol containing phenylthiourea and azo groups was synthesized via three steps. In the first step, 4,4'-bis(thiourea) diphenyl sulfone (BTDS) was obtained from 4,4'- diaminodiphenyl sulfone and ammonium thiocyanate. The second step involved the diazodisation reaction of 4-aminophenol. The third step in the preparation of the monomer was the coupling of bisthiourea (BTDS) with the diazonium chloride in the presence of an alkali which resulted in 4,4'-bis(p-hydroxyphenyl azo thiourea)diphenyl sulfone (HP-ATDS). The final step was the synthesis of polyesters by polycondensation reaction of this monomer with various acid chlorides (both aromatic and aliphatic). The polymers were characterized by solution viscosity, UV-Vis, FT-IR,'H-NMR and TGA. Solubility of the polymers was also tested with different solvents, which is an important parameter for the processablity of the polymer. The synthesis and characterization of the monomer and polymers is discussed herein.
\end{abstract}

Key words: polycondensation, thermal stability, phenylthiourea, sulfone, azo.

\section{INTRODUCTION:}

Phenylthiourea and its derivatives have gained great importance for their excellent properties such as outstanding thermal behavior, high corrosion resistance, good chemical resistance and low inflammability [1-3]. Frignani et al. [4], Chang et al.[5] and Ozcan et al.[6] have investigated the corrosion inhibition property of phenylthiourea towards steel in acidic media.

Magdy et al., [7-8] have recently studied higher thermal stabilizing potency of phenylthiourea and reported that it can be used as a stabilizer for PVC (poly vinyl chloride). John et al.[9] demonstrated high erosive wear and scratch behavior of materials containing amide group. Corte et al.[10] developed adsorption resins consisting of phenylthiourea group for separating heavy metals. Claudia et al.[11] developed benzoylthiourea solid supported liquid membrane system to recover mercury and lead, the two highly toxic elements of great environmental concern. Caihau et al.[12] studied the adsorption properties of the resin containing formaldehyde and thiourea.

Furthermore, in opto-electronics, organic nonlinear optical (NLO) materials containing thiourea molecule have been paid much attention because of their promising potential application in optical information processing, integrated optics and telecommunication [13]. Zhao et al.[14] observed that organic compounds containing thiourea group with large delocalized $(\mathrm{Pi})$ electron system may exhibit extremely larger nonlinear responses, fast switching times and high laser damage thresholds. Moreover, thiourea molecule has large dipole moment [15] and has ability to form extensive network of hydrogen bonds [16]. Pluta et al.[17] have investigated different thioureas, and found that these compounds have attractively high value of third-order optical susceptibility. The replacing oxygen of the $\mathrm{C}=\mathrm{O}$ of urea by its sulfur counter part brings in general quite a large increase of efficiency of the third order optical processes [18].

Work related to polymers containing phenylthiourea in the polymer backbone is relatively scarce. Nouria et al. [19] reported the synthesis of 1methacryloyl-3-phenylthiourea and pyrolysis of its polymer. Francois et al.,[20] synthesized main chain chiral polythiourea. Deutschmann et al.[21] prepared polymeric mesoions using polythiourea. In general, aromatic polymers with thiourea group encounter processing difficulties due to limited solubility in organic solvents and high glass transition temperature. Chain stiffness is the result of intermolecular hydrogen bonding between thiourea groups [22]. The commercial use of these materials is often limited due to their low solubility and poor processability. Modification of high performance materials by increasing the solubility and lowering the transition temperature while maintaining thermal stability are of particular interest. Introducing flexible aliphatic linkages into polymer backbone has been successful in enhancing the solubility [23]. Moreover, polymers containing aryl sulfone linkages are amorphous, have lower glass transition temperature and show good mechanical properties [24-25]. Aromatic polymers that contain aryl sulfone linkages generally have greater chain flexibility, improved solubility and are more amenable for processing than their corresponding polymers without these groups in the polymer backbone [26-27]. The sulfone group (- $\left.\mathrm{SO}_{2}-\right)$ also provides polymer chain with lower energy of internal rotation [28-29].

Polymers containing azo group are of interest for possible use in extreme temperature conditions and are capable of being spun into high modulus fibers [30]. The azo group $(-\mathrm{N}=\mathrm{N}-)$ when incorporated into the polymer backbone imparts color to the polymer [31]. The azo chromophore provides fascinating area of study for photo chemists due to its cis-trans isomerism exhibited by this group and effect on thermal and photochromic properties [32]. The azo $(-\mathrm{N}=\mathrm{N})$ group is one of the most widely used and exhaustively studied chromophore in the field of opto-electronics due its liquid crystalline properties [33]. Shockravi et al.[34] reported the synthesis of polyamide containing sulfide and sulfoxide group. Toader et al.,[35] synthesized polyesters containing azo group.

Based upon the consideration of the above advantages of phenylthiourea, sulfone and azo groups, it is proposed to synthesize a new generation of thermally stable polymers containing these groups. Synthesis of polymers with azo, sulfone $\left(-\mathrm{SO}_{2}-\right)$ and phenylthiourea groups in the polymer backbone is a relatively unexplored area, evident from the literature survey. This aspect motivated us to develop polymers containing above-mentioned groups in the polymer backbone, which are anticipated, to be incombustible, to possess high corrosion, chemical and wear resistant with excellent mechanical properties. Because of the importance of azo and phenylthiourea containing compounds and in continuance of our interest in synthesis of azo-based compounds [3639], we report herein the synthesis of new dihydroxy diazo monomer and the resulting polymers with azo, sulfone and phenylthiourea in the polymer back bone. Polycondensation reaction of this monomer with terephthaloyl chloride (TPC), adipoyl chloride (AC) and azeloyl chloride (AZC) resulted in one fully aromatic and two semi-aromatic azo phenylthiourea esters. Solubility of the polymers was also tested with different solvents, which is an important parameter for the processability of the polymers.

\section{EXPERIMENTAL}

\section{Materials}

All chemicals used in this work were purchased from Lancaster UK. 4,4'- diaminodiphenyl sulfone and 4,4'-aminophenol were recrystallized from ethanol. Pyridine was kept over $\mathrm{KOH}$ for 24 hours and distilled before use.

$N, N^{\prime}$-dimethylacetamide(DMAc), $N, N^{\prime}$-dimethyl formamide(DMF), and dimethylsulphoxide (DMSO) were stored over $\mathrm{KOH}$ for 24 hours and then distilled over calcium hydride at reduced pressure. Thionyl chloride, methanol and chloroform were purified according to the standard procedures [40].

\section{Instruments}

UV-Vis measurements were recorded in DMSO (UV-Grade) using Shimadzu UV- 1601 spectrometer. Infrared spectroscopy measurements were performed on Perkin-Elmer system 1760 FTIR spectrometer. The ${ }^{1} \mathrm{H}-\mathrm{NMR}$ spectra and ${ }^{13} \mathrm{C}-\mathrm{NMR}$ were recorded in DMSO-d solution using $200 \mathrm{MHz}$ and $75 \mathrm{MHz}$ spectrometer respectively. Thermogravimetric analysis (TGA) was 
performed using Perkin-Elmer analyzer under $\mathrm{N}_{2}$ atmosphere, at a heating rate of $10^{\circ} \mathrm{C} / \mathrm{min}$ with a sample weight of $3-5 \mathrm{mg}$. Solubility test was carried out by taking $0.005 \mathrm{~g}$ of the sample and treating with $1 \mathrm{~cm}^{3}$ of the solvent at room temperature. Inherent viscosities were determined by using an Ubbelohde viscometer at a concentration of $0.5 \mathrm{~g} \mathrm{dl}^{-1}$ in DMSO at $30^{\circ} \mathrm{C}$.

\section{Synthesis of poly (sulfone phenylthiourea azo ester) s (PSPAE)}

The synthetic route for the preparation of the monomer (HP-ATDS) is shown in Scheme -1 and 2. Stability of phenylthiourea towards strong alkali and in diazodization reaction (exothermic) has already been established [41]. The procedure for the synthesis of the monomer is in accordance with the reported procedure [42-43]. Terephthalic acid (TPC), Adipoyl chloride (AC), Azeloyl chloride (AZC) were prepared according to the reported procedure [42] and purified by distillation under reduced pressure.

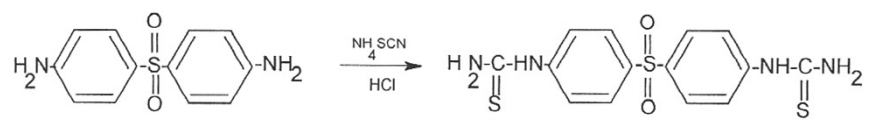

Scheme 1. Preparation of 4, 4' -bis(thiourea)diphenyl sulfone(BTDS)

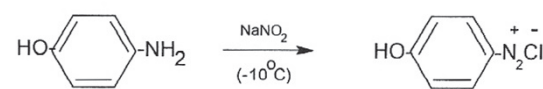<smiles>NC(=S)Nc1ccc(S(=O)(=O)c2ccc(NC(N)=S)cc2)cc1</smiles>

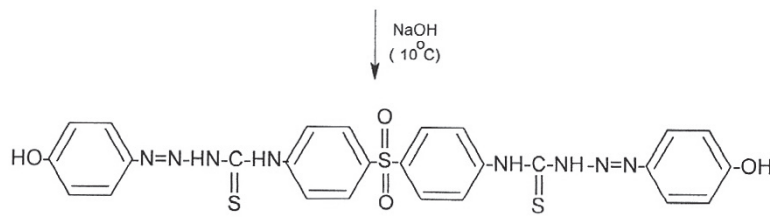

(1)

Scheme 2. Preparation of $4,4^{\prime}$-bis(p-hydroxy phenyl azo thiourea)diphenyl sulfone (HP-ATDS)

The synthesis of polyesters was carried out as follows:

Polycondensation reaction of the monomer 4,4'-bis(p-hydroxy phenyl azo thiourea)diphenyl sulfone (HP-ATDS) with various diacid chlorides including $\mathrm{TPC}, \mathrm{AC}$, and AZC is shown in Scheme-3.

(1)

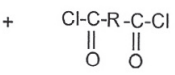

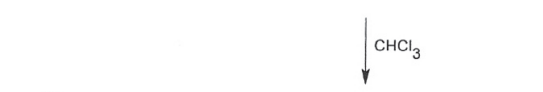<smiles></smiles>

$R=-\quad-\left(\mathrm{CH}_{2}\right)_{4} ; \quad-\left(\mathrm{CH}_{2}\right) ;$

Scheme 3. Synthesis of poly(sulfone phenylthiourea azo ester)s (PSPAE)

This was carried out according to the procedure reported by Margon et al.[44]. One equivalent of the monomer was stirred with aqueous sodium hydroxide in 1:2 mol ratio until a clear solution was obtained. To this, 0.05 gram of sodium lauryl sulfate was added and stirred in a high-speed blender under dry nitrogen atmosphere at room temperature. One equivalent of the diacid chloride in minimum volume of freshly distilled chloroform was then quickly added. The emulsified reaction mixture was vigorously stirred for 20 minutes and then poured into acetone in order to coagulate the polymer. The precipitated polymer was filtered, washed several times with water, dilute sodium carbonate $(5 \%)$ solution and subsequently with acetone. It was then dried under vacuum at $65^{\circ} \mathrm{C}$ until a constant weight was obtained.
All the polymers such as PSPAE-TPC, PSPAE-AC and PSPAE-AZC were obtained by condensing the monomer (HP-ATDS) with various diacid chlorides including TPC, AC and AZC respectively.

The ${ }^{1} \mathrm{H}-\mathrm{NMR}$ (Fig.1), FT-IR (Fig.2), and elemental analysis of bistiourea (BTDS) and the prepared monomer (HP-ATDS) are shown in the Table-1. The FT-IR (Fig 3 \& Fig 4),'H-NMR (Fig.6) and UV-Vis data of synthesized polymers are shown in the Table-2. The yield of polymers and their viscosity are reported in Table-3.
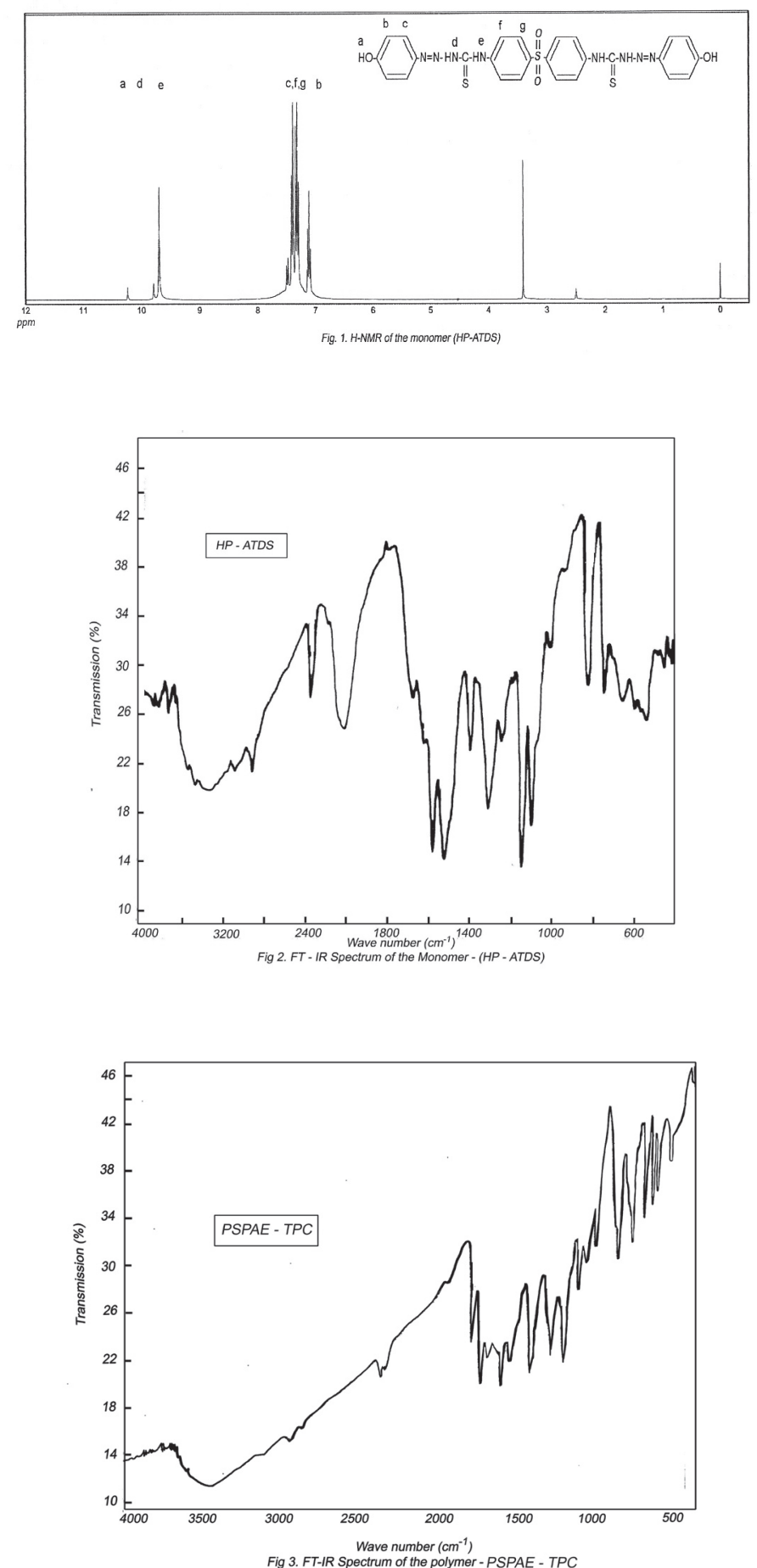

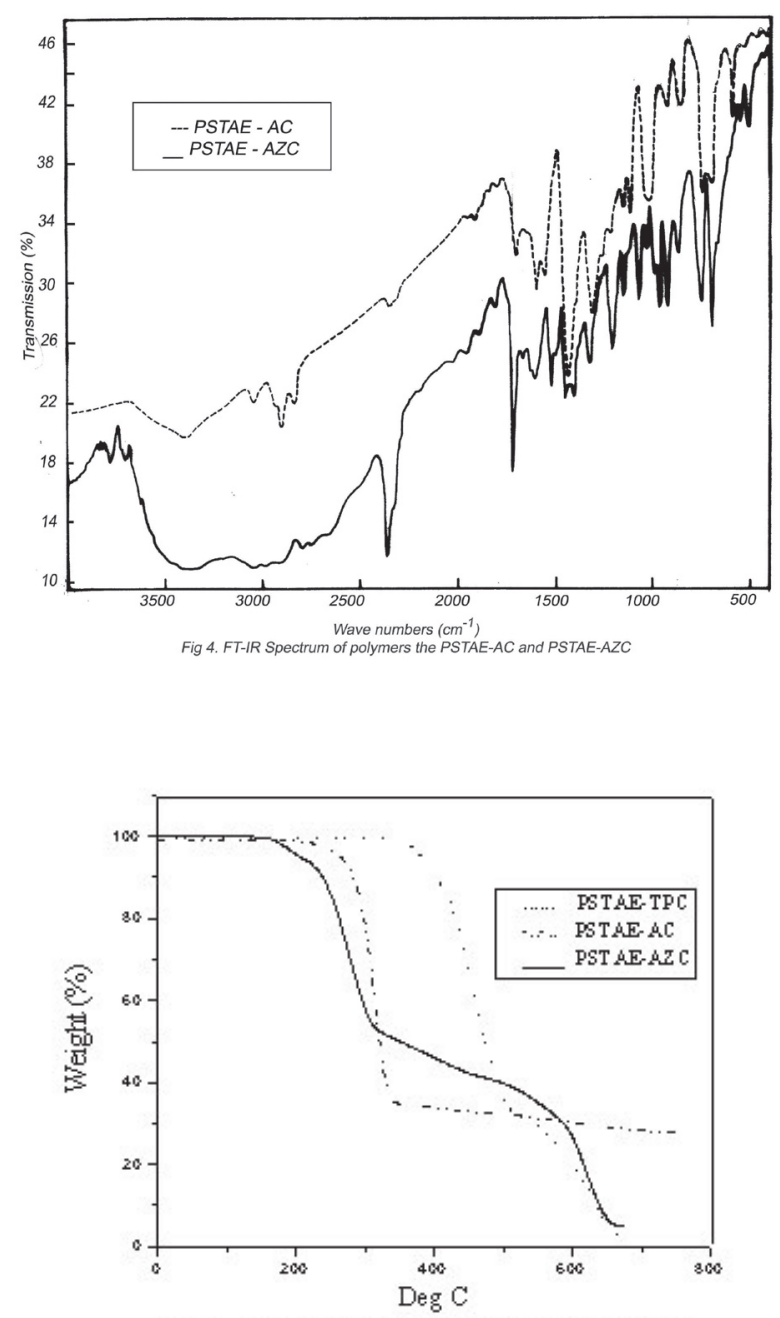

Fig 5. Thermogravimetric curve of the polymers

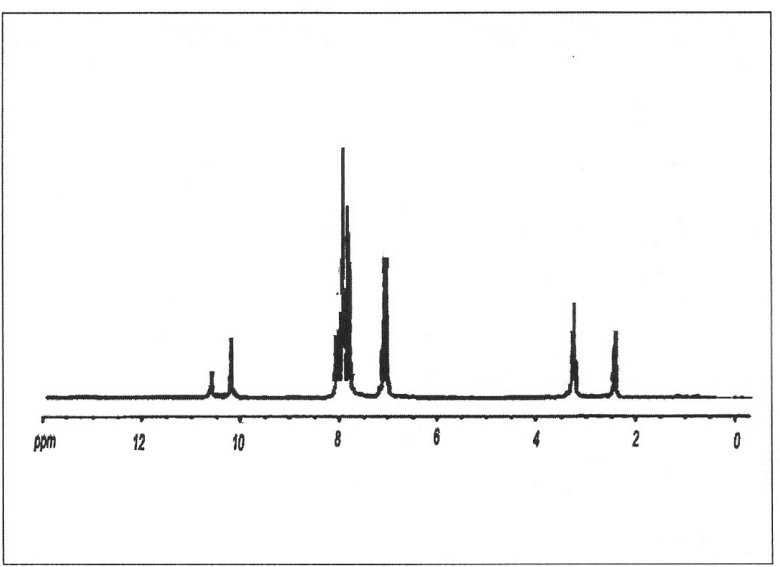

Fig 6. H-NMR Spectrum of the Polymer - PSTAE-TPC
Table 1.- Characterization of substrates.

\begin{tabular}{|c|c|c|c|c|c|c|c|c|c|c|}
\hline \multirow[t]{3}{*}{ Substrates } & \multirow[t]{3}{*}{$\mathrm{IR}\left(\mathrm{KBr} \mathrm{cm}^{-1}\right)$} & \multirow{3}{*}{$\begin{array}{l}\text { HNMR } \\
\left.\text { (DMSO- } \mathrm{d}_{6}, \delta, \mathrm{ppm}\right)\end{array}$} & \multicolumn{8}{|c|}{ Elemental analysis } \\
\hline & & & \multicolumn{4}{|c|}{ Calc. } & \multicolumn{4}{|c|}{ Found } \\
\hline & & & $\mathrm{C}$ & $\mathrm{H}$ & $\mathrm{N}$ & $\mathrm{S}$ & $\mathrm{C}$ & $\mathrm{H}$ & $\mathrm{N}$ & $\mathrm{S}$ \\
\hline BTDS & $\begin{array}{l}3412 \\
3179 \\
1563,1613 \\
1070,1423 \\
723,813\end{array}$ & $\begin{array}{l}9.89(\mathrm{~s}, 2 \mathrm{H}, \mathrm{NH}) \\
9.16\left(\mathrm{~s}, 4 \mathrm{H}, \mathrm{NH}_{2}\right) \\
7.43(\mathrm{~d}, 4 \mathrm{H}, \text { phenyl }) \\
7.37(\mathrm{~d}, 4 \mathrm{H}, \mathrm{ph} \text { phyl }\end{array}$ & 45.90 & 3.82 & 15.31 & 26.22 & 46.41 & 3.21 & 15.02 & 19.01 \\
\hline HP-ATDS & $\begin{array}{l}3417 \\
3200,2821 \\
1581,1512 \\
1412,1142 \\
758,817\end{array}$ & $\begin{array}{l}10.32(\mathrm{~s}, 2 \mathrm{H}, \mathrm{OH}) \\
9.11(\mathrm{~s}, 2 \mathrm{H}, \mathrm{NH}) \\
9.73(\mathrm{~s}, 2 \mathrm{H}, \mathrm{NH}) \\
7.66(\mathrm{~d}, 4 \mathrm{H}, \mathrm{Phenyl}) \\
7.54(\mathrm{~d}, 4 \mathrm{H}, \mathrm{Pheny}) \\
7.12(\mathrm{~d}, 4 \mathrm{H}, \text { phenyl) } \\
6.83(\mathrm{~d}, 4 \mathrm{H}, \text { phenyl }\end{array}$ & 51.48 & 3.63 & 18.48 & 15.84 & 51.22 & 3.74 & 18.37 & 14.97 \\
\hline
\end{tabular}

Table 2.- Characterization of polymers.

\begin{tabular}{|c|c|c|c|}
\hline Polymer & $\operatorname{IR}\left(\mathrm{KBr} \mathrm{cm}^{-1}\right)$ & $\begin{array}{c}\text { H-NMR } \\
(\text { DMSO-d } 6, \delta, p p m)\end{array}$ & $\begin{array}{l}\text { UV-Vis } \\
\text { (DMSO) } \\
\lambda \max (n+m)\end{array}$ \\
\hline PSTAE-TPC & $\begin{array}{l}3411 \\
3170 \\
1732 \\
1544,1512 \\
1142,1414 \\
742,812\end{array}$ & $\begin{array}{l}10.55(\mathrm{~s}, 2 \mathrm{H}, \mathrm{NH}) \\
10.21(\mathrm{~s}, 2 \mathrm{H}, \mathrm{NH}) \\
7.84(\mathrm{~d}, 2 \mathrm{H}, \text { phenyl }) \\
7.61(\mathrm{~d}, 4 \mathrm{H}, \text { pheny1 }) \\
7.22(\mathrm{~d}, 4 \mathrm{H}, \text { phenyl }) \\
6.43(\mathrm{~d}, 4 \mathrm{H}, \text { phenyl })\end{array}$ & 261,359 \\
\hline PSTAE-AC & $\begin{array}{l}3410 \\
3328 \\
1731 \\
1549,1521 \\
1142,1419 \\
751,811\end{array}$ & $\begin{array}{l}10.51(\mathrm{~s}, 2 \mathrm{H}, \mathrm{NH}) \\
10.17(\mathrm{~s}, 2 \mathrm{H}, \mathrm{NH}) \\
7.71(\mathrm{~d}, 2 \mathrm{H}, \mathrm{phenyl}) \\
7.53(\mathrm{~d}, 4 \mathrm{H}, \mathrm{pheny}) \\
7.39(\mathrm{~d}, 4 \mathrm{H}, \mathrm{pheny}) \\
6.49(\mathrm{~d}, 4 \mathrm{H}, \mathrm{pheny1}) \\
3.64\left(\mathrm{~s},-\mathrm{O}-\mathrm{CH}_{2}-\right) \\
2.54\left(\mathrm{~s},-\mathrm{CH}_{2}-\mathrm{CH}_{2}\right)\end{array}$ & 259,344 \\
\hline PSTAE-AZC & $\begin{array}{l}3432 \\
2914 \\
1730 \\
1561,1517 \\
1137,1413 \\
753,821\end{array}$ & $\begin{array}{l}10.38(\mathrm{~s}, 2 \mathrm{H}, \mathrm{NH}) \\
10.19(\mathrm{~s}, 2 \mathrm{H}, \mathrm{NH}) \\
7.72(\mathrm{~d}, 2 \mathrm{H}, \text { phenyl }) \\
7.31(\mathrm{~d}, 4 \mathrm{H}, \text { phenyl }) \\
7.11(\mathrm{~d}, 4 \mathrm{H}, \text { phenyl }) \\
6.47(\mathrm{~d}, 4 \mathrm{H}, \text { phenyl }) \\
3.83\left(\mathrm{~s},-\mathrm{O}-\mathrm{CH}_{2}-\right) \\
2.51\left(\mathrm{~s},-\mathrm{CH}_{2}-\mathrm{CH}_{2}\right)\end{array}$ & 253,327 \\
\hline
\end{tabular}

Table- 3.- Specification of polymers

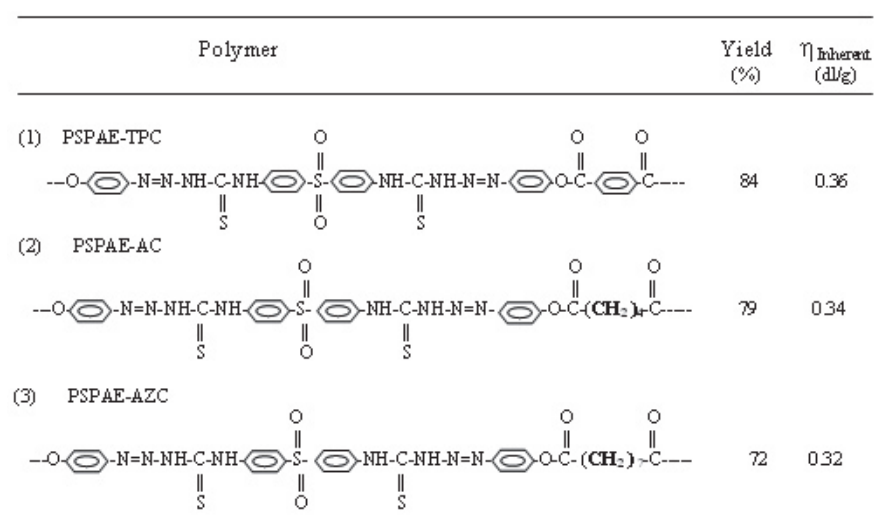


Table 4.- The solubility behavior of the polymer ${ }^{\text {a. }}$

\begin{tabular}{llllllll}
\hline Polymer & Solvent & & & & & \\
\cline { 2 - 6 } & DMSO & DMF & DMAc & m-cresol & Pyridine & THF & Dioxane \\
\hline
\end{tabular}

\begin{tabular}{llllllll}
\hline PSTAE-TPC & ++ & + & +- & - & - & - & - \\
PSTAE-AC & ++ & ++ & + & +- & - & - & - \\
PSTAE-AZC & ++ & ++ & + & +- & - & - & - \\
\hline
\end{tabular}

a solubility: ++ : soluble at room temperature; + : soluble on heating +- : partially soluble on heating: - : insoluble

Table 5.- Thermal analysis data.

\begin{tabular}{lrcc}
\hline Polymer & $\mathrm{T}_{0}\left({ }^{\circ} \mathrm{C}\right)$ & $\mathrm{T}_{10}\left({ }^{\circ} \mathrm{C}\right)$ & $\begin{array}{c}\text { Char Yield at } \\
700^{\circ} \mathrm{C}(\%)\end{array}$ \\
\hline PSTAE-TPC & 340 & 403 & 14 \\
PSTAE-AC & 221 & 288 & 11 \\
PSTAE-AZC & 182 & 234 & 10 \\
\hline
\end{tabular}

\section{RESULTS AND DISCUSSION}

\section{Characterization of Monomer}

According to IR spectra that are shown in the fig.2, the presence of a band at $3417 \mathrm{~cm}^{-1}\left(-\mathrm{N}-\mathrm{H}\right.$ asymmetric stretching), $511 \mathrm{~cm}^{-1}$ (N-C-N) and $1583 \mathrm{~cm}^{-1}$ (-N-H deformation) respectively confirmed the presence of thioamide group. IR spectrum of the HP-ATDE showed peak at $1412 \mathrm{~cm}^{-1}$ confirming the presence of $(\mathrm{C}=\mathrm{S})$ group. The presence of $\left(\mathrm{CS}_{\text {sym-stretching }}\right)$ and $\left(\mathrm{CS}_{\text {asym-stretching }}\right)$ was observed at frequency 758 and $712 \mathrm{~cm}^{-1}$ respectively. Azo $(-\mathrm{N}=\mathrm{N}-)$ stretching frequency appeared at $1417 \mathrm{~cm}^{-1}$ and overlapped with $(\mathrm{C}=\mathrm{S})$ vibrations. Presence of broad absorption peaks at 3200 for $(-\mathrm{OH})$ and a peak at $1132\left(-\mathrm{SO}_{2}-\right)$ confirmed the structure of the monomer (HP-ATDS).

According to ' $\mathrm{H}-\mathrm{NMR} \delta_{\mathrm{H}}\left(\mathrm{d}_{6}\right.$-DMSO), $200 \mathrm{MHz}$ ) of monomer (HP-ATDS) showed peaks at about $\delta 10.32(\mathrm{~s}, 2 \mathrm{H}, \mathrm{OH}), 9.10(\mathrm{~s}, 2 \mathrm{H}, \mathrm{NH}), 9.73(\mathrm{~s}, 2 \mathrm{H}, \mathrm{NH})$, 7.66(d,4H,phenyl), 7.54 (d, 4H,phenyl), 7.12 (d, 4H,phenyl), 6.83 (d, $4 \mathrm{H}$,phenyl); 39.93.

${ }^{13} \mathrm{CNMR}\left(\mathrm{d}_{6}\right.$-DMSO) $\delta 179.9,139.7,129.72,129.16,122.78,124.1$,

\section{Characterization of polyesters}

Polycondensation reaction of the monomer HP-ATDS with various diacid chlorides including TPC, AC and AZC led to preparation of one fully aromatic and two semi-aromatic polyesters (Scheme-3). Structure of these polymers was characterized by UV-Vis,'H-NMR and IR (Table - 2). The representative

FT-IR spectra are shown in the Fig. 3 and Fig.4 respectively. The UVVis spectra of polyesters showed the presence of two bands. The $\lambda \max$ in the UV region was observed at $259 \pm 08 \mathrm{~nm}$, whereas in the visible region it was observed at $344 \pm 18$. The absorption in the UV region is associated with $\pi \rightarrow \pi^{*}$ transitions and those in the visible region is associated with $\mathrm{n} \rightarrow \pi^{*}$ transitions. According to IR spectrum that are given in the Fig.3 and 4, conversion of monomer to polymer was confirmed by disappearance of broad absorption band at $3200 \mathrm{~cm}^{-1}(-\mathrm{OH})$ and appearance of sharp band at $1730-1732 \mathrm{~cm}^{-1}$ for ester group. Presence of absorption bands at $1410-1417 \mathrm{~cm}^{-1}(\mathrm{C}=\mathrm{S}), 804-820$ (C-S stretching ), $3010 \mathrm{~cm}^{-1}$ ( Ar-CH) , 3410-3432 $\mathrm{cm}^{-1}$ (-N-H stretching), $1229-1231(\mathrm{C}-\mathrm{O})$ and $1512-1517 \mathrm{~cm}^{-1}(-\mathrm{N}-\mathrm{H}$ deformation) confirmed the polymer structure. Polymers are obtained in good yield (72-85\%) and inherent viscosity was in the range of $0.32-0.36 \mathrm{dLg}^{-1}$ in DMSO at $30^{\circ} \mathrm{C}$.

According to 'H-NMR $\delta_{\mathrm{H}}\left(\mathrm{d}_{6}\right.$-DMSO), $200 \mathrm{MHz}$ ) of polymer (PSPASTPC) showed peaks at about 10.38-10.55 (s,2H,NH), 10.21-10.19(s,2H,NH), 7.84-7.72 (d,4H,phenyl), 7.61-7.31 (d, 4H,phenyl), 7.22-7.11 (d, 4H,phenyl), 6.43-6.47 (d, 4H,phenyl) ; ${ }^{13} \mathrm{CNMR}$ (d ${ }_{6}$-DMSO) $\delta 180.2,166.68,143.3,129.16$, $125.93,124.1,123.81,39.68$.

Since the stability of polymers in various solvents and the effect of heat on solubility are quite important in selecting of a suitable solvent for processing. Solubility test was carried out for polyesters in different solvents including DMSO, DMF, DMAc and less efficient solvent such as m-cresol (Table - 4). The results obtained on the investigation of solubility of polymers showed the presence of alkyl groups in the semi-aromatic polyesters caused better solubility in comparison to fully aromatic polyesters.

Thermo gravimetric data (Fig.5) obtained for the polyesters, showed a gradual weight loss in the beginning and once the rate of degradation was significant, further loss occurred in a single step. Although, the polymers were dried before the thermal analysis, the initial loss of weight is due to the adsorbed moisture. The initial decomposition temperature $\left(\mathrm{T}_{\mathrm{o}}\right)$ of the polymers was about $182-340^{\circ} \mathrm{C}$. The temperature for $10 \%$ gravimetric loss $\left(\mathrm{T}_{10}\right)$ which is an important criterion for evaluation of thermal stability was found to be in the range of $234-403^{\circ} \mathrm{C}$. Thermal stability of polymers was in the order of

PSPAE-TPC > PSPAE-AC > PSPAE-AZC. The results obtained on thermal studies showed that the fully aromatic one is more stable than the semi aromatic polyesters. The char yields of polymers at $700^{\circ} \mathrm{C}$ were about $10-14 \%$. The results are given in Table -5 .

According to the results obtained, synthesized polyesters have high thermal stability. The fully aromatic one showed better stability than semi-aromatic ones. The higher thermal stability of polymer PSPAE-TPC could be attributed to the incorporation of phenylthiourea and fully aromatic nature of the polymer backbone. Introduction of sulfone linkage, although creates a double bond between the oxygen and one of the phenylene rings, the extended conjugation between two phenylene ring is blocked. Hence thermal stability was slightly decreased when compared to phenylene ring without this group, which is in accordance to the reports in the literature [45]. Fully aromatic polyester led to higher thermal stability due to the intense chain stiffness and intermolecular hydrogen bonding of thiourea groups between the neighboring chains. Introduction of performed thiourea group, phenylation of polymer backbone and symmetry of structures were most important structural modifications for increase in thermal stability.

\section{CONCLUSIONS}

The new monomer HP-ATDS was prepared via three steps.

The 4,4'-bis(thiourea)diphenyl sulfone (BTDS) was prepared from its corresponding diamine namely $4,4^{\prime}$ '-diaminodiphenyl sulfone. Coupling reaction of the diazonium chloride with bisthiourea (BTDS) resulted in the preparation of the monomer 4,4' -bis(p-hydroxy phenyl azo thiourea )diphenyl sulfone (HPATDS). A series of polyesters were synthesized by polycondensation of the monomer with aromatic and aliphatic diacid chlorides.

Polymer samples showed good thermal stability due to the presence of phenylthiourea, phenylation of backbone and symmetry. The improved solubility is attributed to the presence of flexible groups such as sulfone and alkyl groups. The synthesized monomer and polymers were characterized by elemental analysis, UV- Vis, FT-IR,'H-NMR spectroscopic techniques. The polymers were also studied for their thermal behavior using TGA technique. Inherent viscosities of the prepared polymers were determined by Ubbelohde Viscometer. The solubility behavior of the polymers was studied with different solvents.

From this investigation, it may be concluded that the polyesters synthesized as above are soluble and thermally stable polymers.

\section{ACKNOWLEDGEMENT:}

Author M.Sivadhayanithy gratefully acknowledges T.R.Padmanabhan and S.Mahalakshmi for their encouragement and Amrita Vishwa Vidyapeetham University for providing necessary facilities.

\section{REFERENCES:}

1. O.L.Riggs."Corrosion Inhibitors", 21. O.C.Nathan, Nace, Houston, N.Y.1998

2. Jesus Valdes-Martinez, Simon Hernandez, Georgina Espinosa-Perez, Carmina A. Persto, Anne K. Hermetet, Kristin D. Haslow. J. Mol. Struct. 608, 77(2002).

3. Ol'ga Hritzova, Juraj Cernak, Peter Safar, Zdenka Frohlichova, Ingeborg Csoregh. J.Mol. Struct. 743, 299 (2005)

4. A.Frignani, C. Monticelli, F. Zucchi, G.Trabanelli, Mater. Chem. Phys. 929, 403(2005).

5. C. B. Shen, S.G. Wang, H. Y. Yang, K. Long, Fu-Hui Wang. Corros. Sci. 48, 1655(2006)

6. M. Ozcan, I. Dehri, M. Erbil. J. Ap. Susc.236, 155(2004)

7. Magdy W. Sabaa, Rima R. Mohamed, Ahmady. A.Yassin., Polym. Degrad. Stabil.81, 37(2003)

8. Magdy.W.Sabaa, Riham R.Mohamed, Ahmady.AYassin, Polym. Degrad. Stabil. 81, 431(2003)

9. John, Jayashee Bijwe, U.S, Tewari, B. Venkatraman. Wear. 249, 702 (2001) 
10. Herbert Corte, Harlod Heller, Michael Lange, Otto Netz., US Patent., No.39947(1976)

11. Claudia Fontas, Manuela Hidalgo, Victoria Salgado, Enriqueta Antico. Anal. Chim.Acta., 547, 255(2005).

12. Caihau Ni, Changhai Yi, Zhiyun Feng., J.apsusc., 82(13), 3127 (2001).

13. W.Q.Zhou, R.D.Lu,X.Wang, J.molstruct (Theochem)., 624, 123 (2003).

14. B.Zhao, C.Chen, Z.Zhou,Y.Cao, M.Li ., J.Mater.Chem., 10,1581 (2000).

15. Bornsten,in: .H.Hellwege, A.M.Hellwege (Eds), Numerical Data and Functional Relations in science and technology Group II, Springer, Berlin, 584 (1982).

16. A.Masunov, J.J.Dannenberg, J.Phys.Chem., 13(104), 806 (2000).

17. T.Pluta,A.J.Sadlej., J.Chem.Phys., 114(1), 136 (2001).

18. TS Lee, DY Kim, XL Jiang, L Li, J Kumar.S., Makromol.Chem.Phys., 198(7), 2279 (2003).

19. Nouria a.Al-Awadi and Maher Z.Elsanbee, J. Polymer Degrad. Sabil., 50(3), 323 (1995).

20. Francois Touchard, Fabienna Fache, Marc Lemaire., Eur. J.Org. Chem., 2, 3787 (2000).

21. Thomos Deutschmann, Helmut Ritter., Macromol. Rapid. Commun.,17 (10), 723 (1996).

22. T.K.Venkatachalam, E.Sudbeck, F.M.Uekun., J. Mol Struct., 751, 41 (2005).

23. M.Balasubramainan, M.J.Nanjan and M.Santappa., Makromol.Chem., 180, 2517 (1982)

24. Chiriac C, Stille JK., Makromol.,10, 712 (1974).

25. Brode GL, Kawakami JH., Kwaitkowski GT., Bedwin AW., J. Polym Sci Part A: Polym Chem.,12, 575 (1974).

26. Saxena A, Rao VL, Prabakaran PV, Ninan KN., Eur.Polym. J., 39, 401 (2003).

27. S.M.Ataei, Y.Sarrafi, M.Hatami and L. A. Feizi., Eur. Polym. J., 41, 491, 2005.

28. Bottino FA, Pasquale GD, Scalia L, Pollicino.A., Polymer., 42, 3323 (2001)
29. Gutch PK, Banerjee S, Jaiswal DK., J. Appl. Polym. Sci, 89, 691 (2003).

30. F.P.Gay and F.Agolini, US Patent No.3,455,879 (1979).

31. J.E.Riordon and H.S.Blair., Polymer., 20, 196 (1979)

32. V.Rajendran and M.J.Nanjan,.., J. Appl. Polym Sci ., 37, 3281 (1989).

33. Almeria Natanjohn and Paul Rochon, Chem. Rev., 102, 4139 (2002).

34. A. Schockravi, Shahram Mehdipour-Ataei Ebrahim Abouzari-Lotf, Ali Yousefi., Eur.Polym J. 42, 133 (2006).

35. S.Alazaroaie, V.Toader, I.Carlescu, ,K.Kazmierski, D.Scutaru, N.Hurduc and C.I.Simionesu., Eur. Polym. J. 39, 1333 (2003).

36. Ramaswamy Mani, C. Rangaswamy, K.Ramarajan, L.Ravi kumar., Makromol. Chem. Rapid Commun., 9, 417 (1998).

37. A.Muthusamy, S.Karthikeyan, K.Ramarajan and L.Ravikumar., J. Indian Chem Soc., 78, 23 (2001).

38. C. Rengasamy, L.Ravikumar, and K.Ramarajan., J. Indian Chem Soc., 69, 788 (1992)

39. D.Jayaprakash, L.Ravikumar and M.J.Nanjan., Die Makromol. Chem. Rapid Commun., 2611 (1981).

40. B.S.Furniss, A.J.Henna Ford, P.W.G.Smith and A.R. Tatchell, "Vogel's Text book of practical organic chemistry"., 5 th Edn. ELBS, London, (1995).

41. R.L Frank and Paul V.Smith., Organic syntheses, 28, 735 (1955).

42. James F Wolfe, Bock H Loo and F.E.Arnold., Macromolecules., 14, 915 (1981).

43. Heinrich Zollinger h.c., "Diazo Chemistry I, Formation and Reactions of Triazenes", VCH, mbH, DOI: 10.1002/3527601724.ch13, (2004) Online.

44. P.W.Margon, "Condensation Polymer by Interfacial and solution Methods", Wiely, NY, 119 (1965)

45. Cassidy P.E., "Thermally stable polymers., Dekker, NY, (1980). 